\title{
POLIMENTO ELETROLÍTICO EM FIOS DE NiTi*
}

\author{
Laís Ávila de Oliveira Silva ${ }^{1}$ \\ Natália Isabel de Azevedo Lopes² \\ Pedro Damas Resende ${ }^{3}$ \\ Vicente Tadeu Lopes Buono ${ }^{4}$
}

\section{Resumo}

A aplicação de ligas de NiTi como biomateriais exige que sua superfície tenha um excelente acabamento final, para garantir a alta resistência à corrosão e a biocompatibilidade. $\mathrm{O}$ polimento eletrolítico é um processo capaz de diminuir as imperfeições da superfície, sem alterar as propriedades do material, e de formar uma fina camada protetora de $\mathrm{TiO}_{2}$. Nesse estudo, foram realizados eletropolimentos em fios superelásticos e com memória de forma, usando dois eletrólitos ácidos distintos. A partir dos resultados obtidos, foi possível concluir que a solução de ácido sulfúrico produz superfícies mais homogêneas do que o de ácido perclórico, para os mesmos tempos de polimento, e se apresenta como uma boa alternativa para o tratamento superficial de ligas superelásticas e martensíticas de para sua aplicação como biomateriais.

Palavras-chave: NiTi; Superelástico; Efeito memória de forma; Polimento eletrolítico; Biomaterial.

\section{Abstract}

\section{ELECTROPOLISHING OF NiTi WIRES}

The application of NiTi alloys as biomaterials requires that their surface shows an excellent finishing, to guarantee high corrosion resistance and biocompatibility. Electrolytic polishing is a process that can reduce the surface imperfections without changing the properties of the material, forming a thin protective layer of $\mathrm{TiO}_{2}$. In this study, the electropolishing was performed on superelastic and shape memory wires using two different acid electrolytes. From the results obtained, it was possible to conclude that the solution of sulfuric acid produces more homogeneous surface than perchloric acid, to the same polishing times, and presents itself as a good alternative for the surface treatment of superelastic alloys and martensitic of to their application as biomaterials.

Keywords: NiTi; superelasticity; Shape memory effect; Electrolytic polishing; Biomaterial.

1 Graduanda do curso de Engenharia Metalúrgica da Universidade Federal de Minas Gerais UFMG, Belo Horizonte, Minas Gerais, Brasil.

2 Engenheira Química, doutoranda, Departamento de Engenharia Metalúrgica e de Materiais, Universidade Federal de Minas Gerais - UFMG, Belo Horizonte, Minas Gerais, Brasil.

3 Graduando do curso de Engenharia Metalúrgica da Universidade Federal de Minas Gerais UFMG, Belo Horizonte, Minas Gerais, Brasil.

4 Físico, doutor, Professor Titular, Departamento de Engenharia Metalúrgica e de Materiais, Universidade Federal de Minas Gerais - UFMG, Belo Horizonte, Minas Gerais, Brasil. 


\section{INTRODUÇÃO}

As ligas equiatômicas de níquel e titânio (NiTi) apresentam duas propriedades formidáveis: o efeito de memória de forma e a superelasticidade. Estes dois efeitos estão relacionados à transformação martensítica da liga, uma transformação de fase adifusional nos sólidos, na qual os átomos se movem cooperativamente por um mecanismo de cisalhamento, sem alterar a composição química da matriz, e se rearranjam em uma nova estrutura cristalina mais estável. No efeito memória de forma, o material se encontra na fase de baixa temperatura e tem a capacidade de recuperar sua forma original após sofrer grandes deformações, sendo necessário somente o aquecimento acima de sua temperatura de transformação. Já a superelasticidade apresenta-se na fase de alta temperatura das ligas, onde o material encontra-se totalmente austenítico e deformações decorrentes de um carregamento mecânico são recuperadas ao se retirar a carga aplicada [1].

Para a aplicação das ligas NiTi como biomaterial, existe uma constante preocupação com efeitos alergênicos, de toxicidade e carcinogenicidade associados à dissolução e à liberação de íons níquel no organismo, devido à corrosão e à degradação do material durante seu uso [2]. No processo de produção das ligas NiTi, ao se aquecer a liga ao ar, uma camada complexa composta de uma mistura de óxidos de titânio e de fases ricas em níquel é formada em sua superfície. $\mathrm{O} \mathrm{TiO}_{2}$ é extremamente estável e inerte, enquanto fases ricas em níquel apresentam baixa resistência à corrosão. Além disso, as ligas de NiTi são de difícil usinagem [1], o que resulta geralmente em superfícies com alta concentração de defeitos. Uma liga NiTi biocompatível deve apresentar uma camada superficial livre de irregularidades, com apenas um filme fino de $\mathrm{TiO}_{2}$ exposto ao ambiente.

Entre os tratamentos de superfície tradicionalmente aplicados em biomateriais, o processamento eletroquímico geralmente produz o melhor acabamento superficial, com camadas de óxido resistentes e suficientemente finas para acompanhar deformações no substrato sem trincar [3]. O polimento eletrolítico é capaz de dissolver seletivamente irregularidades superficiais e fases ricas em níquel, além de formar concomitantemente um filme protetor de $\mathrm{TiO}_{2}$. Além disso, eletropolimentos evitam a formação de martensita induzida por tensão na superfície das ligas, resultado que não seria alcançado pelo polimento mecânico. Um bom polimento eletrolítico exerce, ainda, uma grande influência nas propriedades e na estrutura de recobrimentos protetivos aplicados nos materiais [4].

Embora eletropolimentos já sejam amplamente aplicados comercialmente, existem poucas publicações descritivas sobre os processos e seus parâmetros. Pohl et al. [5] estudaram os efeitos do polimento eletrolítico na rugosidade superficial de fios de NiTi com memória de forma nos estados austenítico e martensítico. Nesse trabalho, o eletropolimento nas estruturas austeníticas foi realizado usando um eletrólito constituído de ácido perclórico e ácido acético. Para as amostras no estado martensítico foi utilizado um eletrólito de ácido nítrico e metanol. Após eletropolimento das amostras, observou-se uma diminuição na rugosidade e uniformização da superfície, além de um aumento na resistência à corrosão. Em um estudo utilizando diversas soluções aquosas e alcoólicas de ácido sulfúrico, Fushimi et. al. [6] obtiveram os melhores resultados de rugosidade superficial em uma liga com memória de forma usando uma solução metanólica de ácido sulfúrico. Simka et al. [7] avaliaram a influência da composição do eletrólito e das condições de operação na qualidade da superfície de uma liga de NiTi. Superfícies morfologicamente uniformes foram obtidas apenas quando foram usados eletrólitos 
contendo ácidos hidrofluorídrico e sulfúrico. Também foi observado um aumento na resistência à corrosão após eletropolimento, esterilização e passivação das amostras.

O objetivo desse trabalho foi comparar dois eletrólitos ácidos e identificar qual gera superfícies com melhor acabamento, com maior simplicidade e menor tempo de processamento, tanto em fios superelásticos e como em fios com memória de forma, visando sua aplicação como biomaterial.

\section{MATERIAIS E MÉTODOS}

Neste estudo, foram usados fios, com diâmetro igual $1,0 \mathrm{~mm}$, superelásticos - SE (temperatura final da transformação reversa $A_{f}$ nominal de $0^{\circ} \mathrm{C} \pm 5^{\circ} \mathrm{C}$ ) e com memória de forma superelásticos - MF - (Af nominal de $\left.70^{\circ} \mathrm{C} \pm 5^{\circ} \mathrm{C}\right)$ produzidos pela Stanford Advanced Materials (Irvine, CA, EUA). O aspecto superficial do material foi analisado por Microscopia Eletrônica de Varredura - MEV (Inspect S50, FEI, Hillsboro, EUA) e a composição química das ligas foi determinada semiquantitativamente por Espectroscopia de Energia de Raios X - EDS (Genesis, EDAX Inc., Mahwah, EUA). Os fios foram caracterizados por difratometria de raios X - DRX (PW 1710, Philips-PANalytical, Almelo, Holanda), para identificar as fases cristalográficas presentes no material. Para remoção da camada de óxido mais grosseira dos fios conforme recebidos, foi feita uma decapagem ácida com solução de peróxido de hidrogênio $\left(\mathrm{H}_{2} \mathrm{O}_{2}\right)$ e ácido fosfórico $\left(\mathrm{H}_{3} \mathrm{PO}_{4}\right)$ em água a $80^{\circ} \mathrm{C}$, até completa remoção do óxido [8]. Os fios decapados foram novamente analisados por MEV/EDS e DRX.

O polimento eletrolítico foi realizado em fios decapados, limpos em ultrassom durante 15 minutos em banho de acetona, seguido por 15 minutos em água deionizada. Foi utilizada uma célula eletroquímica padrão, com contraeletrodo de platina e eletrodo de referência $\mathrm{Ag} / \mathrm{AgCl}$, ligados a um potenciostato (VersaSTAT 3, Princeton Applied Research, Berwyn, EUA). Foram comparados dois eletrólitos ácidos, um constituído por $21 \%$ de ácido perclórico $\left(\mathrm{HClO}_{4}\right)$ em ácido acético $\left(\mathrm{CH}_{3} \mathrm{COOH}\right)$ [5] e outro de $20 \%$ ácido sulfúrico $\left(\mathrm{H}_{2} \mathrm{SO}_{4}\right)$ em metanol $\left(\mathrm{CH}_{3} \mathrm{OH}\right)$ [6]. Para determinação do patamar de corrente onde ocorre o eletropolimento, foi feita uma varredura potenciodinâmica de $0 \mathrm{~V}$ a $10 \mathrm{~V}$ com velocidade de $0,1 \mathrm{~V} . \mathrm{s}^{-1}$. Definidos, em cada fio, os patamares de corrente para cada eletrólito, o eletropolimento foi realizado mantendo-se fixo o potencial referente ao patamar de corrente, durante quatro tempos distintos (30, 60, 120 e 240 segundos). As amostras foram pesadas antes e após o eletropolimento, para determinação da perda média de massa. Após os testes, as amostras foram novamente analisadas por MEV/EDS, para avaliar qual condição de eletropolimento gera uma superfície com melhor acabamento.

\section{RESULTADOS E DISCUSSÃO}

Os resultados das análises de superfície por MEV/EDS das amostras de fios de NiTi, antes e após decapagem, são mostrados na Figura 1 e na Tabela 1. Observa-se que a camada de óxido superficial dos fios apresentava aspecto muito grosseiro e completamente trincado, impróprio para aplicação como biomaterial, e, mesmo após limpeza em ultrassom, foi detectada por EDS a presença de contaminantes diversos, como carbono, alumínio e silício. Na decapagem, a maior parte dos óxidos e dos contaminantes pode ser removida. No entanto, resquícios da camada grosseira de 
$\mathrm{TiO}_{2}$, marcas de trefilação e diversas irregularidades superficiais ainda são observadas (Figuras 1b e 1d).

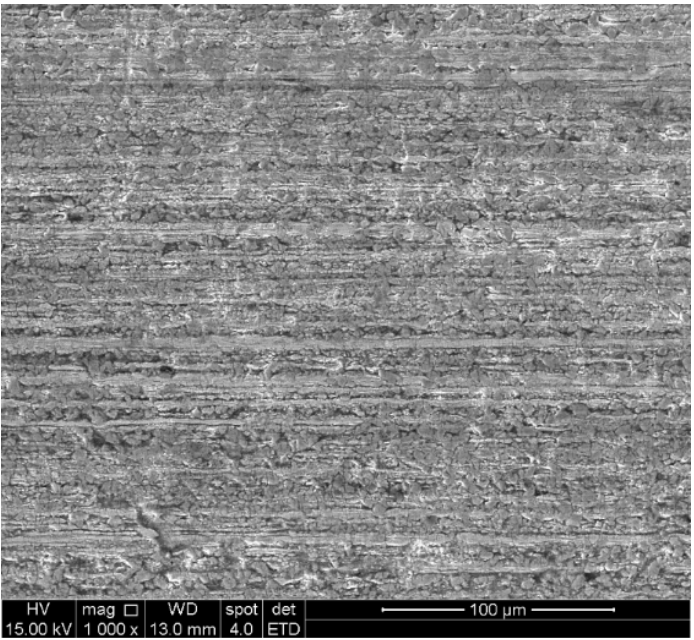

(a)

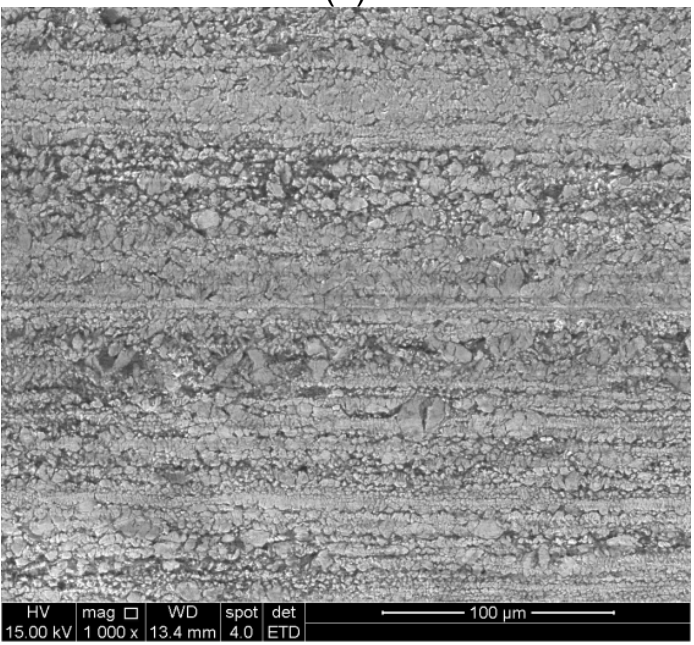

(c)

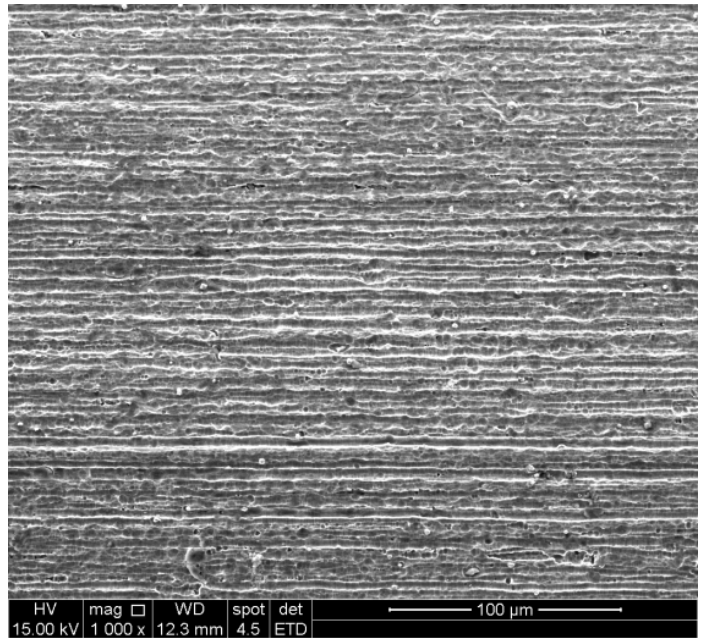

(b)

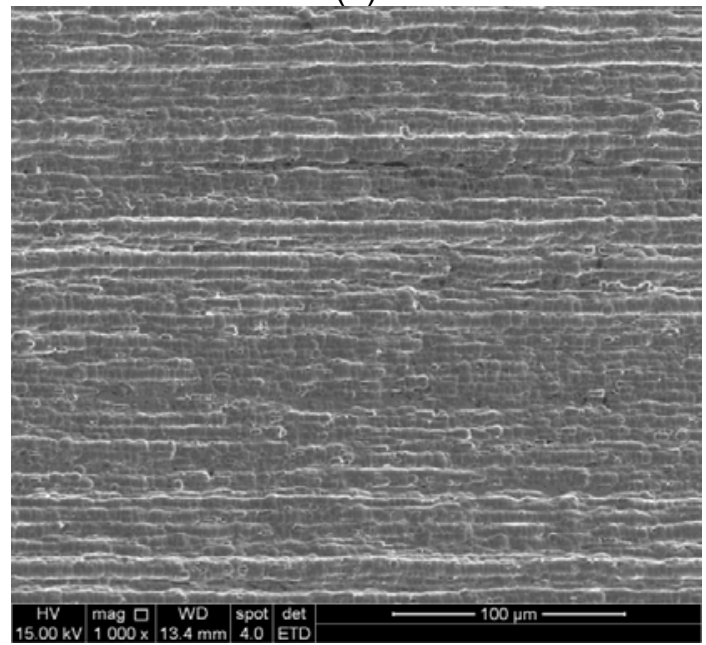

(d)

Figura 1. Resultados de análises de superfície por MEV de fios de NiTi: (a) SE conforme recebido; (b) SE após decapagem; (c) MF conforme recebido; (d) MF após decapagem.

Tabela 1. Resultado de análises semiquantitativas por EDS em fios de NiTi

\begin{tabular}{clcccccc}
\hline \multirow{2}{*}{ Amostra } & \multicolumn{7}{c}{ Elemento (\%) } \\
\cline { 2 - 8 } & $\mathbf{T i}$ & $\mathbf{N i}$ & $\mathbf{C}$ & $\mathbf{O}$ & $\mathbf{S i}$ & $\mathbf{A l}$ \\
\hline \multirow{2}{*}{$\mathrm{SE}$} & conforme recebido & 35,5 & 15,6 & 21,3 & 25,9 & 1,1 & 0,6 \\
\cline { 2 - 8 } & após decapagem & 36,1 & 43,7 & 3,4 & 16,8 & - & - \\
\hline \multirow{2}{*}{ MF } & conforme recebido & 34,5 & 29,8 & 17,3 & 16,7 & 1,0 & 0,7 \\
\cline { 2 - 8 } & após decapagem & 44,5 & 55,5 & - & - & - & - \\
\hline
\end{tabular}

$\mathrm{Na}$ análise por difração de raios $\mathrm{X}$ do fio superelástico, foram identificadas apenas as fases cristalinas B2 (NiTi na forma austenítica) e óxido de titânio $\left(\mathrm{TiO}_{2}\right)$. Já para os fios com memória de forma, além dessas fases, observou-se a existência da martensita B19' e da fase R. Nota-se, ainda, a ocorrência da fase $\mathrm{Ni}_{3} \mathrm{Ti}$ no fio com memória de forma antes da decapagem. O surgimento de tal fase ocorre quando a formação do óxido de titânio não se processa de maneira uniforme e fases ricas em níquel ficam expostas na superfície, prejudicando sua resistência à corrosão e a biocompatibilidade do material. Após decapagem, apenas as fases presentes na matriz dos fios são observadas (Figura 2). 


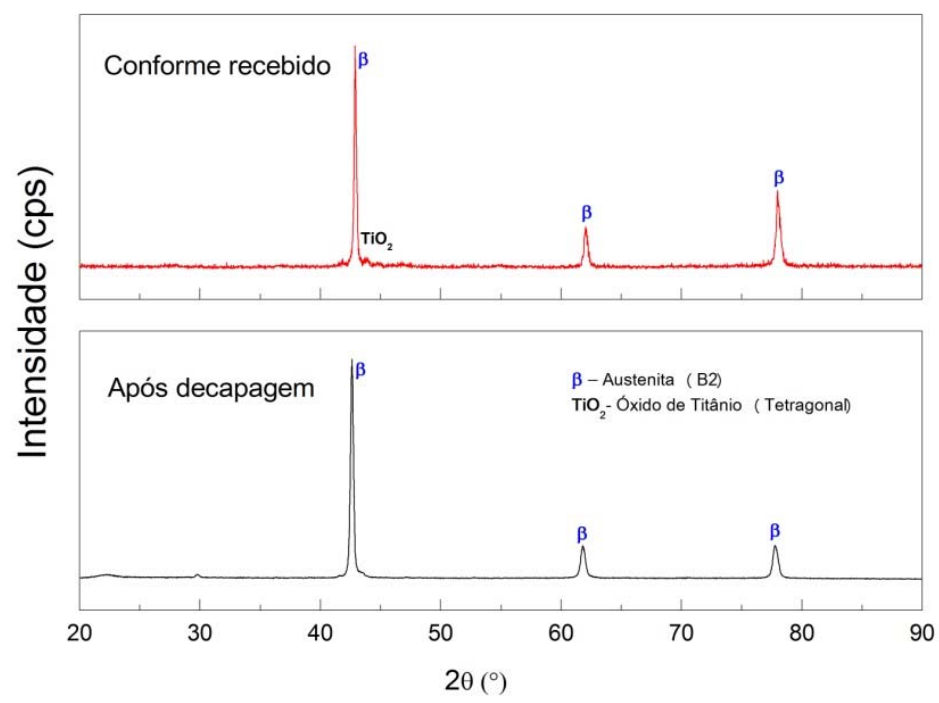

(a)

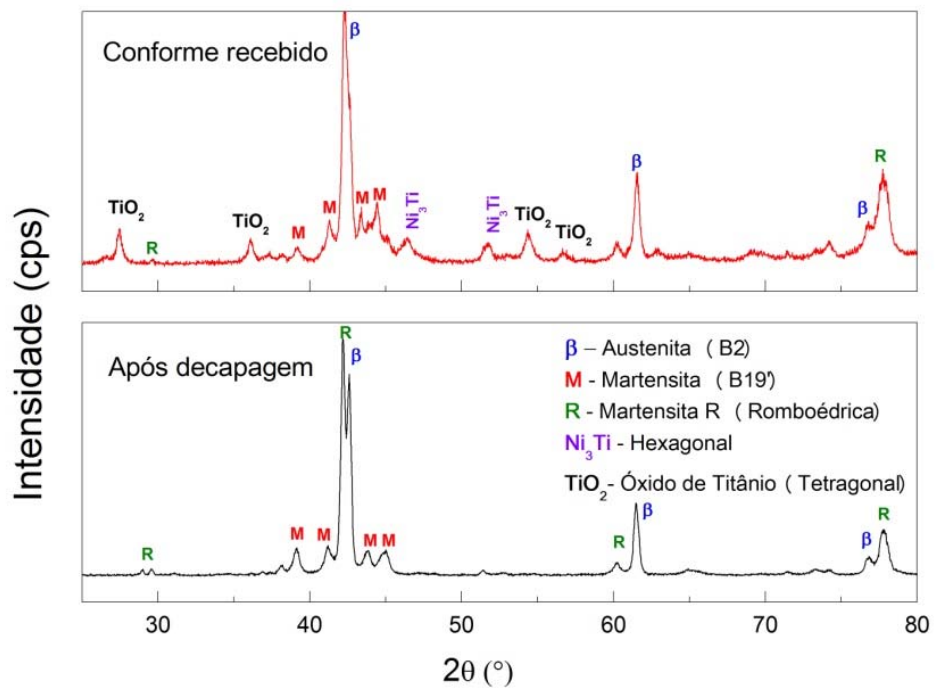

(b)

Figura 2. Difratometria de raios $\mathrm{X}$ em fios de NiTi antes e após decapagem: (a) superelásticos; (b) memória de forma.

Polimentos eletrolíticos convencionais utilizam, em geral, eletrólitos de alta viscosidade e baixa condutividade, tais como ácidos concentrados (sulfúrico, perclórico, clorídrico e fluorídrico) em soluções ionizadoras (álcool, ácido acético ou água). Esses eletrólitos são capazes de focar o campo elétrico nas irregularidades superficiais da amostra, resultando em sua dissolução preferencial e, consequentemente, na homogeneização e no polimento da superfície. Sabe-se que a região ótima para o eletropolimento ocorre onde o processo é controlado por transporte de massa, correspondente ao patamar de corrente da curva obtida por uma varredura potenciodinâmica. Na Figura 3, são mostradas as curvas de densidade de corrente versus potencial para polimento em fios superelástico e com memória de forma, para os dois eletrólitos avaliados. 


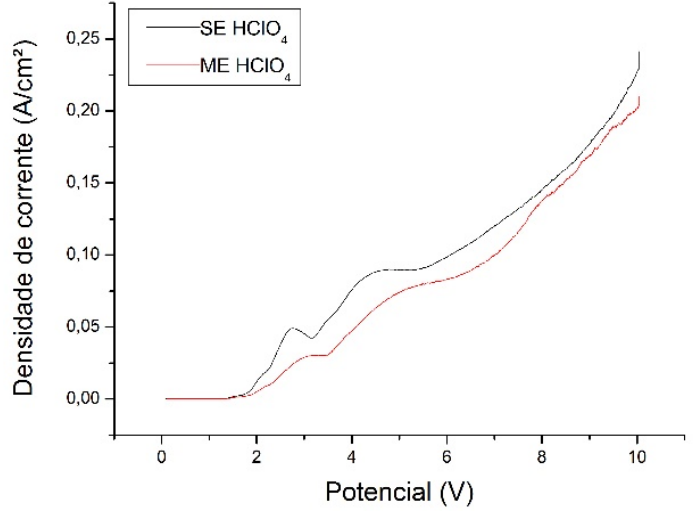

(a)

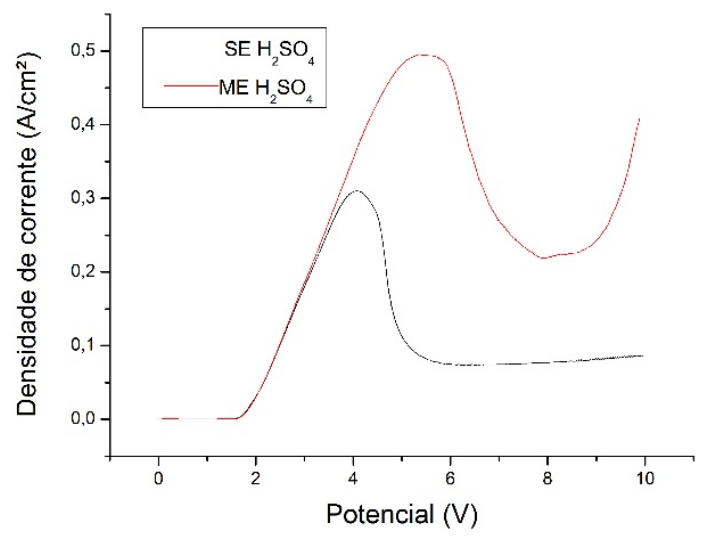

(b)

Figura 3. Curvas de densidade de corrente versus potencial para polimento em fios superelástico e com memória de forma: (a) eletrólito $\mathrm{HClO}_{4}$; (b) eletrólito $\mathrm{H}_{2} \mathrm{SO}_{4}$.

Os valores de potenciais de eletropolimento, correspondentes às regiões de patamares de correntes (Figura 3), definidos para realização do polimento eletrolítico são apresentados na Tabela 2 . Os polimentos foram realizados em triplicada, para cada eletrólito, em quatro tempos diferentes. O resultado da variação média percentual de massa após eletropolimento são mostrados na Figura 4. Conforme esperado, quanto maior o tempo de polimento, maior é a perda de massa observada. Nota-se, ainda, que a perda de massa foi mais severa quando o eletrólito de ácido sulfúrico foi utilizado. Observa-se, também, que no polimento usando $\mathrm{H}_{2} \mathrm{SO}_{4}$, o fio superelástico apresentou perda percentual de massa maior do que o fio com memória de forma.

Tabela 2. Potenciais do patamar de polimento eletrolítico

\begin{tabular}{lcc}
\hline \multirow{2}{*}{ Amostra } & \multicolumn{2}{c}{ Potencial de polimento (V) } \\
\cline { 2 - 3 } & \multicolumn{2}{c}{ Eletrólito } \\
& $\mathrm{HClO}_{4}$ & $\mathrm{H}_{2} \mathrm{SO}_{4}$ \\
\hline Superelástico & 5 & 7 \\
\hline Memória de forma & 5,5 & 8 \\
\hline
\end{tabular}

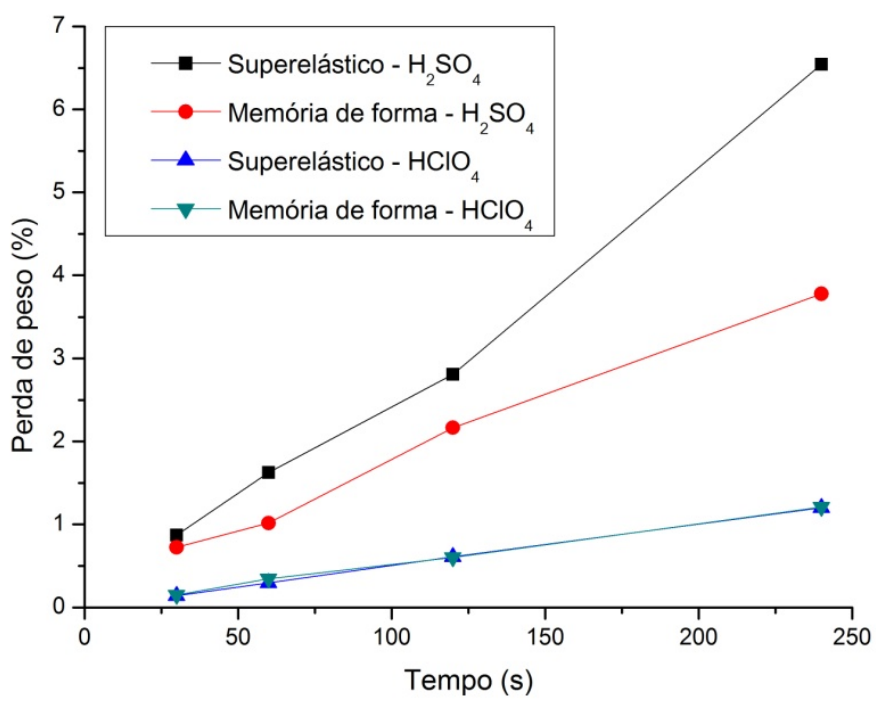

Figura 4. Variação percentual de massa em diferentes tempos de polimento eletrolítico em fios superelásticos e com memória de forma, usando eletrólitos de $\mathrm{HClO}_{4}$ e de $\mathrm{H}_{2} \mathrm{SO}_{4}$. 
$\mathrm{Na}$ análise da morfologia superficial por MEV após polimento eletrolítico, foi possível observar, de uma maneira geral, que as irregularidades dos fios se tornaram menos proeminentes com o aumento do tempo do polimento. Conforme mostrado nas Figuras 5 e 6, o aumento do tempo de polimento provocou melhora no aspecto superficial, tanto para o eletrólito de ácido perclórico como para o de ácido sulfúrico. Também são observados diversos precipitados claros, que, pela análise de EDS, são provavelmente carboneto de titânio. Isso ocorre porque as dissoluções que ocorreram na matriz de NiTi durante o processo de polimento não atacam o $\mathrm{TiC}$ e resultam no revelamento dessas estruturas, distribuídas na matriz dos fios de NiTi.

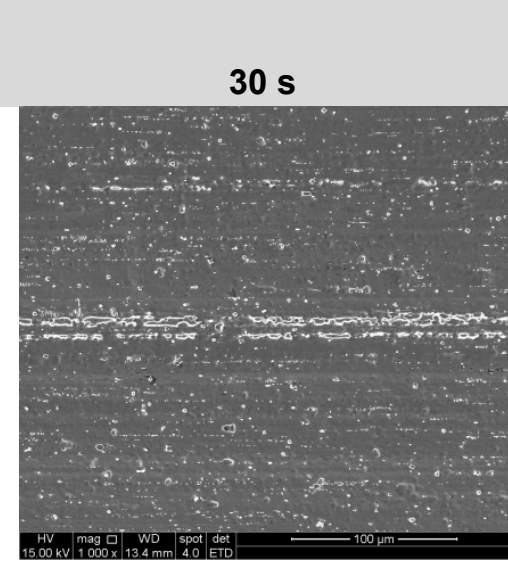

$30 \mathrm{~s}$

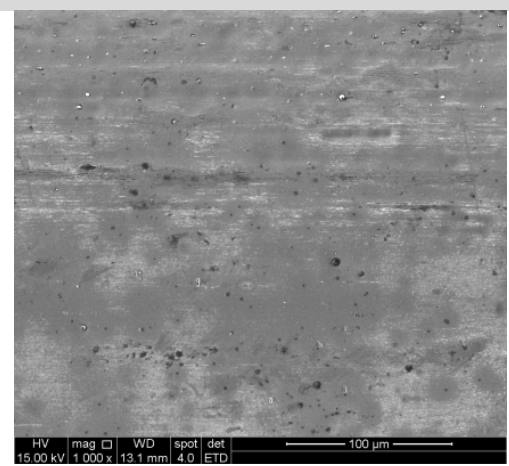

\section{ELETRÓLITO $\mathrm{HClO}_{4}$}

$120 \mathrm{~s}$

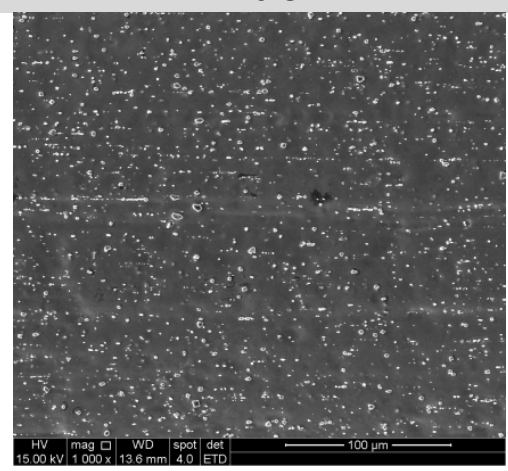

(a)
ELETRÓLITO $\mathrm{H}_{2} \mathrm{SO}_{4}$

$120 \mathrm{~s}$

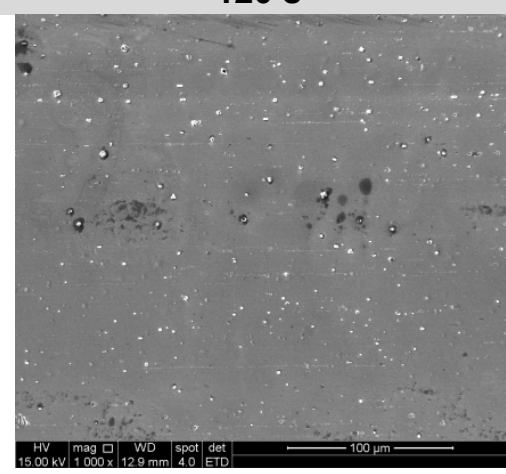

(b)
$240 \mathrm{~s}$

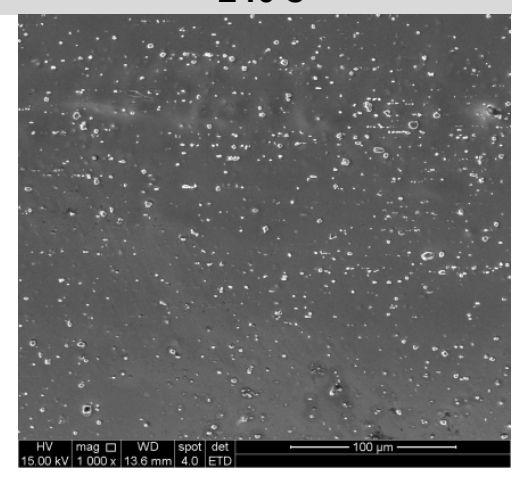

$240 \mathrm{~s}$

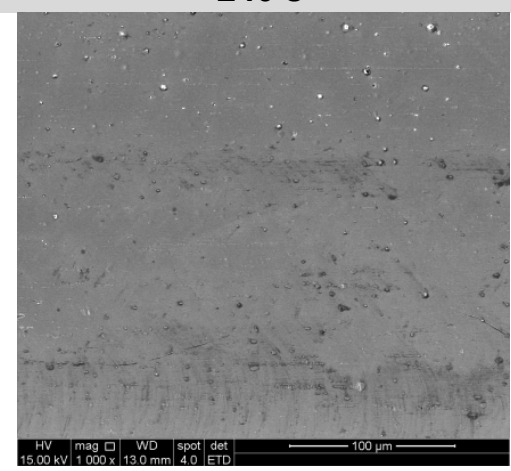

Figura 5. Aspecto superficial das amostras de fios superelásticos de NiTi após polimento eletrolítico: (a) eletrólito de $\mathrm{HClO}_{4}$ em diferentes tempos; (b) eletrólito de $\mathrm{H}_{2} \mathrm{SO}_{4}$ em diferentes tempos.

Pelos resultados de teor de níquel obtido pela análise semiquantitativa por EDS mostrados na Tabela 3, verifica-se que o aumento do tempo de polimento levou a uma diminuição no teor de níquel, aproximando-o do da porcentagem equiatômica esperada para essas ligas. Nos fios polidos eletroliticamente não foi identificado oxigênio, o que mostra que toda a camada inicial de óxido de titânio foi retirada e o novo filme formado é bastante fino. 

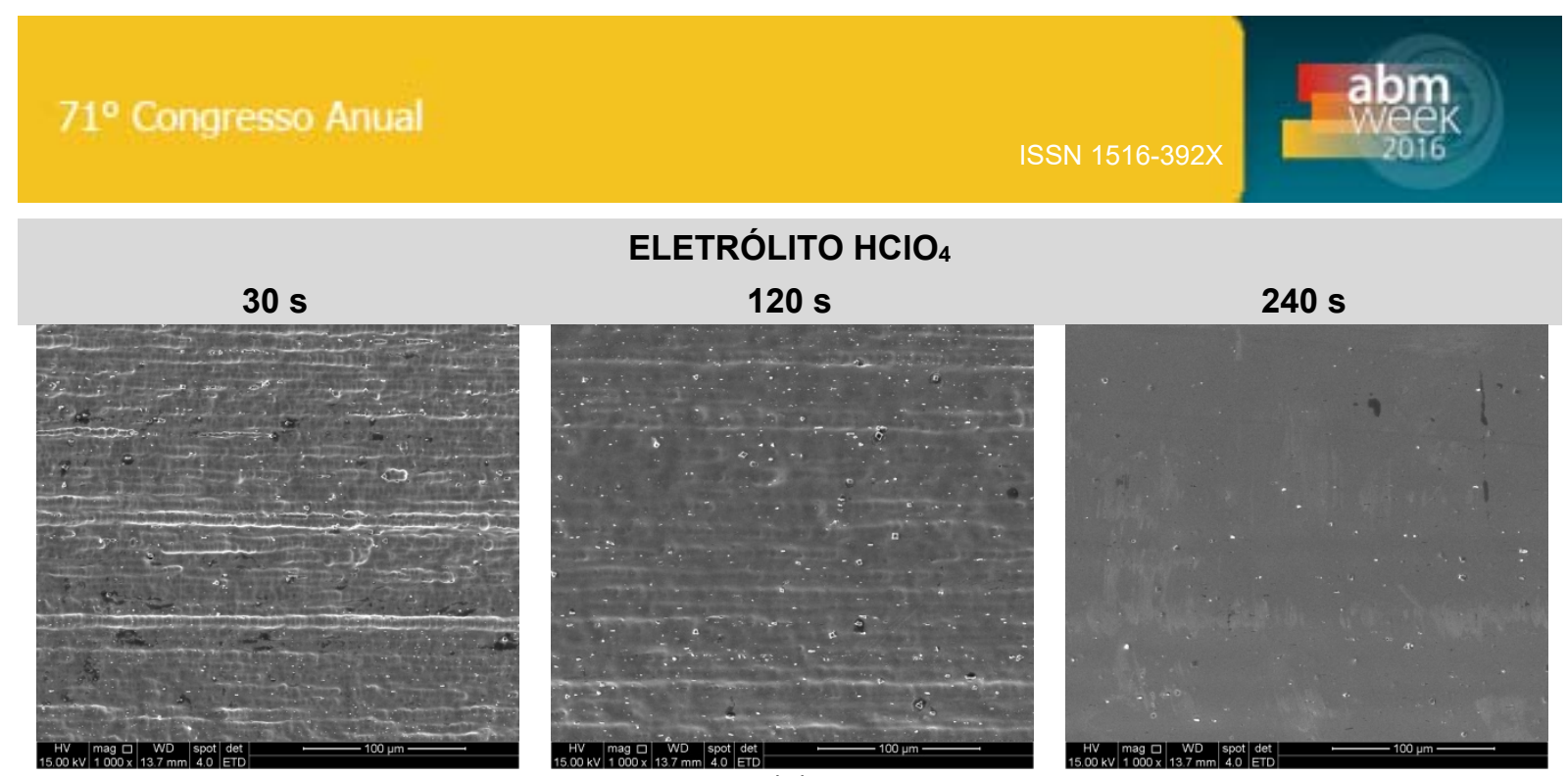

\section{ELETRÓLITO $\mathrm{HClO}_{4}$}

$120 \mathrm{~s}$

$240 \mathrm{~s}$
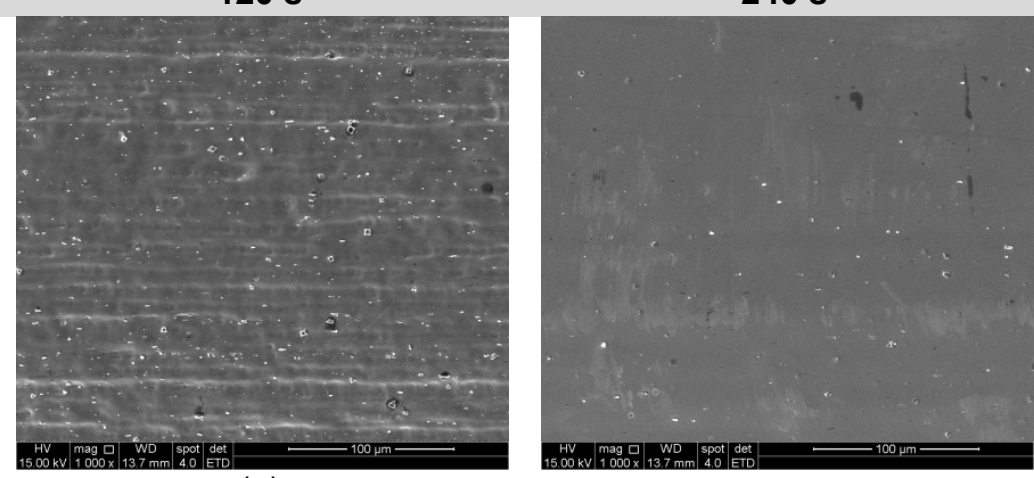

(a)

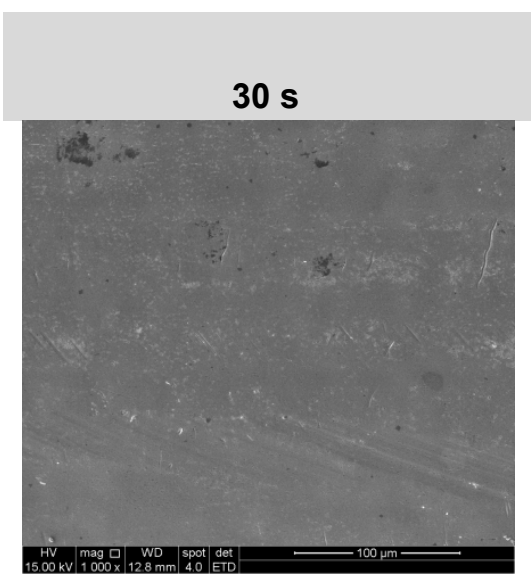

ELETRÓLITO $\mathrm{H}_{2} \mathrm{SO}_{4}$

$120 \mathrm{~s}$

$240 \mathrm{~s}$
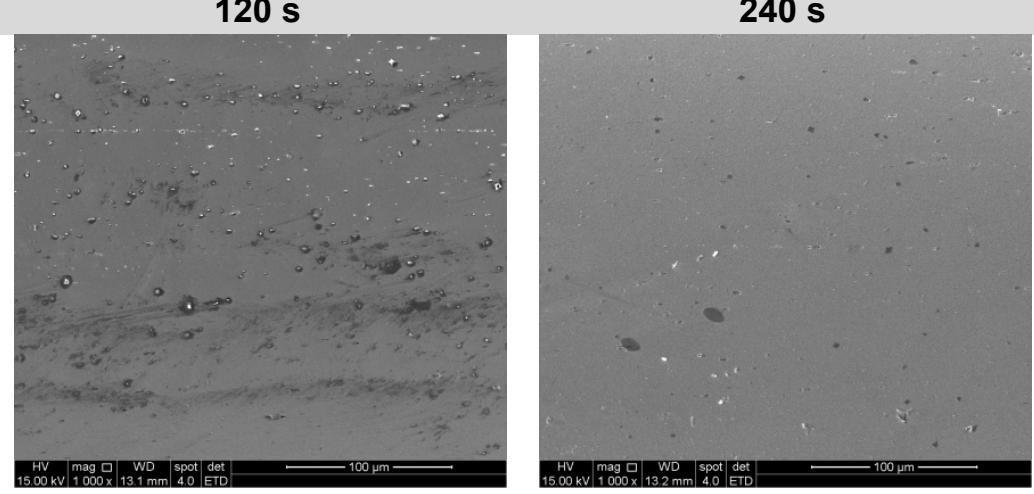

(b)

Figura 6. Aspecto superficial das amostras de fios com memória de forma de NiTi após polimento eletrolítico: (a) eletrólito de $\mathrm{HClO}_{4}$ em diferentes tempos; (b) eletrólito de $\mathrm{H}_{2} \mathrm{SO}_{4}$ em diferentes tempos.

Tabela 3. Resultado de análises semiquantitativas por EDS após polimento eletrolítico

\begin{tabular}{|c|c|c|c|c|c|c|c|c|}
\hline \multirow{5}{*}{ Amostra } & \multicolumn{8}{|c|}{ Ni (\%at.) } \\
\hline & \multicolumn{8}{|c|}{ Eletrólito } \\
\hline & \multicolumn{4}{|c|}{$\mathrm{HClO}_{4}$} & \multicolumn{4}{|c|}{$\mathrm{H}_{2} \mathrm{SO}_{4}$} \\
\hline & \multicolumn{4}{|c|}{ Tempo (s) } & \multicolumn{4}{|c|}{ Tempo (s) } \\
\hline & 30 & 60 & 120 & 240 & 30 & 60 & 120 & 240 \\
\hline Superelástico & 50,9 & 50,6 & 50,5 & 50,1 & 52,5 & 51,6 & 50,3 & 50,1 \\
\hline Memória de forma & 49,8 & 50,6 & 50,4 & 50,8 & 52,1 & 49,2 & 49,6 & 50,2 \\
\hline
\end{tabular}

Idealmente, a remoção de material no polimento eletrolítico deve ser mínima, restrita às imperfeições superficiais e óxidos. Em tempos de polimento muito longos, pontos de corrosão começam a ser formados e por isso o tempo de tratamento deve ser aquele que ofereça o melhor acabamento superficial, no menor tempo possível. Embora ambos os eletrólitos tenham apresentado resultados satisfatórios, o aspecto superficial foi sistematicamente mais homogêneo usando o eletrólito de ácido sulfúrico, para os mesmos tempos de polimento. Além disso, o manuseio do ácido perclórico exige uma série de cuidados especiais, tendo em vista o risco de explosão em decorrência de elevação da temperatura ou contato com determinados materiais, fazendo com que o eletrólito de $\mathrm{H}_{2} \mathrm{SO}_{4}$ seja uma escolha eficaz e mais segura. No entanto, o ácido perclórico é capaz de realizar o polimento com menor remoção de massa, o que pode ser vantajoso em determinadas aplicações. 


\section{CONCLUSÃO}

Nas condições avaliadas, o polimento eletrolítico tornou a superfície dos fios de NiTi mais uniforme, diminuindo consideravelmente as irregularidades inicialmente presentes. Tempos maiores de polimento resultaram em uma maior perda de massa e em um melhor acabamento superficial dos fios. Para os mesmos tempos de polimento, o eletrólito de ácido sulfúrico produziu superfícies mais homogêneas do que o de ácido perclórico e maior remoção de massa. Considerando os resultados obtidos e os riscos de manuseio do ácido perclórico, o eletrólito de $\mathrm{H}_{2} \mathrm{SO}_{4}$ se apresenta como uma boa alternativa para a obtenção de superfícies menos rugosas e livres de defeitos superficiais, adequadas para aplicação do $\mathrm{NiTi}$ na área biomédica.

\section{Agradecimentos}

Os autores agradecem à FAPEMIG, ao CNPq e à CAPES/PROEX pelo apoio financeiro.

\section{REFERÊNCIAS}

1 OTSUKA, K.; WAYMAN, C. M. Shape Memory Materials. 1ed. United Kingdom: Cambridge University Press, 1998. 284p.

2 DENKHAUS, E.; SALNIKOW, K. Nickel Essentiality, Toxicity and Carcinogenicity. Critical Reviews in Oncology / Hematology, v. 42, n. 1, p 35-56. 2002.

3 DUERIG, T. Shape Memory Alloys: Materials for Medical Devices. ASM Handbook, v. 23, p. 237-250, 2012.

4 SHABALOVSKAYA, S.; ANDEREGG, J.; VAN HUMBEECK, J. Critical overview of Nitinol surfaces and their modifications for medical applications. Acta biomaterialia, v. 4, n. 3, p. 447-467, 2008.

5 POHL, M.; HESSIN, C.; FRENZEL, J. Electrolytic processing of NiTi shape memory alloys. Materials Science and Engineering A, v. 378, n. 1-2, p. 191-199, 2004.

6 FUSHIMI, K., STRATMANN, M., HASSEL, A. Electropolishing of NiTi shape memory alloys in methanolic H2SO4. Electrochimica Acta, v. 52, p. 1290-1295, 2006.

7 SIMKA, W., KACZMAREK, M., BARON-WIECHEĆ, A., NAWRAT, G., MARCINIAK, J.,ŻAK, J. Electropolishing and passivation of NiTi shape memory alloy. Electrochimica Acta, v. 55, p. 2437-2441, 2010.

8 OKAZAKI, S.; OHHASHI, T.; NAKAO, S.; HIROSE, Y. HITOSUGI, T.; HASEGAWA, T. Wet etching of amorphous $\mathrm{TiO}_{2}$ thin films using $\mathrm{H}_{3} \mathrm{PO}_{4}-\mathrm{H}_{2} \mathrm{O}_{2}$ aqueous solution. Japanese Journal of Applied Physics, v. 52, n. 098002, p. 1-3, ago. 2013. 